\title{
Crisis Counseling and Intervention in Rural Schools in South Africa
}

\author{
Dr M. A. N. Duma \\ University of Zululand, KwaDlangezwa . 3886, Republic of South Africa \\ Email:dumam@unizulu.ac.za
}

Doi:10.5901/mjss.2014.v5n27p529

\begin{abstract}
The aim of this article is to explore the experiences of teachers on crisis counseling and intervention in rural schools in South Africa. Apart from a literature review on crisis counseling, intervention and prevention in schools, the article reports on a study in which empirical investigation based on quantitative research paradigm was used to collect data from rural school teachers. The literature findings revealed that crisis counseling and intervention is a critical component of school practice in many schools in South Africa. The study further on revealed that empirical findings elicited that education and training received by teachers are largely based on teaching and learning aspects and school management tasks only and no particular attention to crisis counseling, intervention and prevention is evident, yet teachers are expected to function as school- based crisis counselors and interveners in times of crises. The study is concluded by the submission that it is essential for teachers to be trained in crisis counseling and intervention.
\end{abstract}

Keywords: crisis theories, in service teacher training, teaching and learning activities; school management tasks

\section{Introduction}

Since 1994, the enormous expectations imposed on teachers have prompted a significant change in the nature and scale of their accountability. This accountability stretches to all corners of the school, ranging from teaching and learning activities to crisis counseling, intervention, and prevention. It should, however, be noted that education and training received by teachers are largely based on teaching and learning aspects and school management tasks only and no particular attention to crisis counseling and intervention is evident, yet teachers are expected to function as school- based crisis counselors.

The concept of crisis counseling, interventions and preventions is novel to many teachers and this lack of preparation makes the task of crisis counseling, interventions and preventions foreign and uncomfortable to most of them. There is ample evidence that schools are not immune to violence. A series of shootings in classrooms, in trains and in the buses transporting learners to schools, the high death rate due to the HIVIAIDS pandemic, political violence and other traumatic events during the past few years have underscored one of the chief responsibilities faced by school teachers. Escalating crime, including violent crime against both learners and teachers in many rural schools is on record.

With the upsurge of these acts, the demand for crisis counseling, intervention and prevention services in rural schools has increased significantly. Such systematic pressures need to be matched by enhanced support mechanisms in the form of in-service education and training (INSET) programmes for the teachers. INSET, therefore, will not only equip teachers with the tools they require for effective crisis counseling, intervention and prevention obligations, but will also promote their status as school-based crisis counselors.

\section{Literature Review}

\subsection{Conceptualising crisis intervention}

What is crisis intervention? Hendricks and McKean (1995) assert that crisis intervention has been with us the first time one individual in crisis was helped by another. Roberts (1990) states that crisis intervention refers to a therapist entering into the life of the individual to lessen the impact of crisis in order to help mobilise resources for those directly affected. Hendricks and McKean (1995) give the nod to this definition as they confirm that crisis intervention is the timely and effective involvement in the people's lives when stress is too great for them to manage through their usual coping mechanisms. This assertion is also assented by Greenstone and Leviton (2002), as they describe crisis intervention as the act of interrupting the downward spiral skillfully and as quickly as possible and, in so doing, of returning the individual 
to a pre-crisis level of coping.

Myer (2001) identifies three distinct elements involved in the definition of crisis intervention:

- Time-Limit Dimension: crisis limit is time limited, with the time span of not more than six weeks. This call for the interveners to set up appointments with a victim long enough to ensure his physical and psychological safety. Meetings should be designed to help the victim regaining a sense of psychological equilibrium and selfprotection.

- Single -Issue Dimension: the treatment should address a specific issue and try to assist the victim resolve only that concern. This means that the crisis intervention process must be focused on setting and maintaining factual goals. Interveners must concentrate on immediate needs and deal with symptoms that are related to the crisis only.

- Treatment - Dimension: treatment must concentrate on the client's returning to a pre-crisis level of functioning. The interveners must use their energy on what must be done to initiate the process of resolving the crisis.

Roberts (1990) astutely pointed out that crisis intervention is a technique intended to lessen immediate pressures and to restore clients to a level of adjustment. The fundamental goal of helping an individual who is undergoing a crisis is to intervene in such a way as to restore him to his previous level of functioning (Sandoval 2002, France 1990, Hendricks and McKean 1995, Greenstone and Leviton 2002).

These definitions of crisis intervention seem to be valid and useful to interveners as they all emphasise that the focus in crisis intervention is on helping the person in crisis to handle and lessen the impact of the crisis event on his life.

Kanel (2003) argues that no one discipline or school of thought can claim crisis theory as its own, for crisis theory has been derived from a variety of sources such as psychoanalytic, existential, humanistic, cognitive-behavioral and general systems theories. In the same spirit, James and Gilliland (2003) are of the opinion that no single theory or discipline contains every view of human crises or all the models or systems of crisis intervention.

Following hereunder, is a presentation of a brief overview of selected theories relevant to crisis intervention.

\subsubsection{Psycho-Analytic Theory}

This theory is based on the assumption that psychic energy is finite and only a limited exists for individuals. This assumption, according to Kanel (2003) helps to explain the disequilibrium that occurs when a person's usual coping skills fail and his psychological energy is reduced. According to James and Gilliland (2003), this theory is based on the view that the disequilibrium that goes with a person's crisis can be apprehended through gaining access to the individual's unconscious thoughts and past experiences.

\subsubsection{Existential Theory}

The assumption in this theory is that anxiety is a regular part of existence and can help self-development. Kanel (2003) submits that anxiety is a motivator for risk and development, for without anxieties caused by new life situations, people will never develop. This assumption means that all people will suffer in life at one time or another. This theory relates to the victim's acceptance of personal responsibility and realizing that many problems are self-made. In that instance, the victim is empowered with choices that urge him to accept the responsibility for his choices.

\subsubsection{Humanistic Theory}

This theory stresses the importance of relying on the victims to realise their potential in the context of a therapeutic relationship. The focus is on reflective and empathetic techniques. Corsisni and Wedding (1989) in Kanel (2003) contend that these techniques assist the victims to acknowledge and freely express their emotions.

\subsubsection{Basic Crisis Theory}

This theory, according to James and Gilliland (2003), focuses on the understanding of behavior in clients whose grief crises were precipitated by loss. The emphasis is on the immediate resolution of grief after loss. Victims are helped to recognize and correct temporary affective behavioral and cognitive distortions brought about by traumatic events. The resolution of a crisis may lead to a positive outcome and decrease negative behavior.

As mentioned previously, there are many theories about crisis and crisis intervention, not all of which can be accommodated in this article. 


\section{Motivation of the Study}

A cross-section of the field of crisis management reveals that very little research has been conducted on the views of rural teachers on crisis intervention in schools. The relative unavailability of literature on this research problem is itself an indication that research has to be done in order to provide more insight and improved approaches on this issue. Crisis intervention is a skillful intrusion into a personal crisis to defuse a potentially disastrous situation before physical or emotional destruction occurs (Greenstone and Leviton 2002). It makes sense that such a delicate exercise needs a welltrained teacher in crisis intervention, who, in times of need makes quick, accurate, and critical decisions about the victim and mobilises needed resources.

Various factors strengthen the role of teachers in crisis intervention the schools. These factors foster the ability of teachers to evaluate information and press their own interpretation and conceptions, improve the quality of crisis intervention in schools, rationalise the crisis intervention functions and understand the legal implications of crisis intervention.

The researcher, having worked in rural schools as a principal and currently as a university senior lecturer, visiting these schools to lend support to the university student teachers, perceives that rural teachers have difficult experience in crisis intervention in schools and the support from the Department of Education is not evident. The unsatisfactory state of crisis intervention in rural schools in South Africa begs an important question: why, after almost twenty years since the establishment of a democratic education system, weaknesses and shortcomings in crisis intervention in schools continue to persist.

It makes sense that such a delicate exercise needs a well-trained teacher in crisis intervention, who, in times of need makes quick, accurate, and critical decisions about the victim and mobilizes needed resources.

The school system requires that teachers play a vital role in crisis intervention in schools. The demand for crisis intervention services in schools has increased significantly. It is ironic that teachers with no proper training in crisis intervention are expected to deal with the learners in crisis and have to act as crisis interveners.

The following research problem was identified: What are the experiences of teachers in crisis intervention in rural schools in South Africa?

\section{Research Methodology}

To address the research problem, both literature study and empirical investigation based on quantitative research design were undertaken. The researcher consulted literature which is relevant to the topic. This was done to provide a critical synthesis of what has already been written on the topic.

\subsection{Quantitative Research Paradigm}

A survey to gather questionnaire-based data in a real-life setting was used in the study. The research design included the delimitation of the field of survey, the selection of respondents (size of the sample and sampling procedures), the research instruments, namely the questionnaires, a pilot study, the administration of the questionnaires, and the processing of data

\subsection{Population and Sampling}

The researcher used the simple random sampling method to select two hundred teachers from KwaZulu Natal Midlands Cluster's two districts, namely Sisonke and Ugu. This method was favoured for its simplicity, unbiased nature, and its closeness to fulfilling the major assumption of probability, namely that each element in the population stands an equal chance of being selected (Kumar 2014). For ethical reasons, permission to conduct research in schools was sought from the relevant district offices.

\subsection{Instrumentation}

The questionnaire was used as research instrument. This quantitative methodology was chosen in the light of the purpose of the study, the kind of information that was required and the available resources. As McMillan, Schumacher (2006) and Kumar (2010) maintain that questionnaires permit anonymity, preclude possible interviewer biases and permit a respondent sufficient time to consider answers before actually answering. Data provided by questionnaires can be more 
easily analysed and interpreted than the data obtained from verbal responses and lastly, questionnaires can elicit information that cannot be obtained in other methods. The researcher believed that this kind of survey would lead to some truths about the role of learner leadership in rural secondary schools and it would provide information on whether certain generalisations presented in the literature were also true for this population.

\subsection{Format of the Questionnaire}

The questionnaire was divided into four sections, with each section focusing on the aims of the study. Section 1 consisted of questions, which focus on the biographic and general information. This section provided the researcher with an understanding and knowledge of the respondents. Section 2 had closed questions focusing on their experience on crisis intervention in their schools. The respondents were asked to rate their responses according to the following scale: Yes, No and Unsure. Section 3 consisted of open-ended questions, wherein respondents were asked to write down the problems they encounter in crisis intervention in their schools. Sections 4 consisted also of open-ended questions, wherein teachers had to suggest ways that can improve their performance in crisis intervention in their schools.

\subsection{Administration of the Questionnaires}

The researcher conducted a pilot study in six schools in Ugu and Sisonke districts. The schools were part of the general population from which the sample was drawn, but not part of the sample itself. No inherent weaknesses were discovered in the questionnaires and the data solicited confirmed the questionnaires' validity and reliability, consequently there was no need to modify the questionnaires.

In the actual study, the teachers were requested to complete their questionnaires which were later posted to the researcher, using the self addressed envelope supplied with the questionnaire.

The first sample population responses were 130 (65\%) respondents. After the follow-ups, 23 respondents returned the completed questionnaires to make total of 143 responses (72\%). That represented a satisfying response.

\subsection{Data Processing}

After all the questionnaires had been received, the important task was then to reduce the mass of data obtained to a format suitable for analysis. The respondents' responses were coded and frequency distributions were generated.

\section{Findings and Discussion}

\subsection{General and Biographical profile of the Respondents}

When the item of rural teachers' academic qualification was analysed, it was realised that all the respondents had fully completed the information regarding general and biographical data.

Table 1: Teachers' Academic Qualifications

\begin{tabular}{|c|c|c|}
\hline Teachers Qualification & $\mathbf{N}$ & $\%$ \\
\hline Below Matric (Grade 12) & 0 & 0 \\
\hline Matric + 1 ( M+1) & 19 & 13 \\
\hline Matric +2 (M+2) & 31 & 22 \\
\hline Matric+3 and above & 93 & 65 \\
\hline Total & 143 & 100 \\
\hline
\end{tabular}

In Table 1, a total population of $143(\mathrm{n}=143$ ) responded. Table 1 revealed that a high proportion of rural school principals $(65 \%)$ had good academic qualifications. This shows that the education level of the teacher population in rural schools is improving. This high qualification rate can help in empowering teachers with crisis intervention skills. 


\subsection{Teachers 'experiences in crisis intervention in rural schools}

Table 2: Teachers' experiences in crisis intervention in rural schools

\begin{tabular}{|l|c|c|c|c|c|}
\hline Items & & YES & UNSURE & NO & Total \\
\hline \multirow{2}{*}{ The concept of crisis intervention is novel to many rural teachers } & $\mathrm{N}$ & 129 & 14 & 0 & 143 \\
\cline { 2 - 5 } & $\%$ & 90 & 10 & 0 & 100 \\
\hline \multirow{2}{*}{ Crisis intervention is uncomfortable to most rural teachers. } & $\mathrm{N}$ & 129 & 14 & 0 & 143 \\
\cline { 2 - 5 } & $\%$ & 90 & 10 & 0 & 100 \\
\hline \multirow{2}{*}{ Teachers show empathy, warmth and sincerity to learners in crisis } & $\mathrm{N}$ & 123 & 6 & 14 & 143 \\
\cline { 2 - 5 } & $\%$ & 86 & 4 & 10 & 100 \\
\hline \multirow{2}{*}{ Teachers assess crisis situations and the learners in crises. } & $\mathrm{N}$ & 12 & 14 & 117 & 143 \\
\cline { 2 - 5 } & $\%$ & 8 & 10 & 82 & 100 \\
\hline Teachers ensure the safety of the victim learner by minimising the physical and & $\mathrm{N}$ & 0 & 43 & 100 & 143 \\
\cline { 2 - 5 } psychological dangers that may affect him & $\%$ & 0 & 30 & 70 & 100 \\
\hline \multirow{2}{*}{ Teachers begin with interviewing the victim learner to counseling him. } & $\mathrm{N}$ & 43 & 14 & 86 & 143 \\
\hline Teachers have approaches that schools have can employ to discourage and & $\%$ & 30 & 10 & 60 & 100 \\
\hline counteract acts of school violence. & $\mathrm{N}$ & 7 & 7 & 129 & 143 \\
\cline { 2 - 5 } & $\%$ & 5 & 5 & 90 & 100 \\
\hline
\end{tabular}

In Table 2, teachers were required to indicate their experiences in crisis intervention in their schools. They were asked to rate their responses according to the following scale: Yes, No and Unsure.

The concept of crisis intervention is novel to many rural teachers. Table 2 revealed that a majority of the respondents (90\%) indicated that the concept of crisis intervention is novel to many rural teachers. This implies that most schools do not really use teachers as crisis interveners. This is based on the fact that education and training received by most rural teachers are largely based on teaching and learning aspects only and no particular attention to crisis interventions and preventions is evident, yet teachers are expected to function as school- based crisis interveners in times of crises.

Crisis intervention is uncomfortable to most rural teachers. Table 2 further on revealed that a high proportion of respondents (90\%) indicated that crisis intervention is uncomfortable to most rural teachers. Teachers are supposed to play a pivotal role in crisis intervention in schools. It has been previously indicated that the concept of crisis intervention is novel to many teachers. This lack of preparation makes the task of crisis intervention foreign and uncomfortable to most of them. Escalating crime, including violent crime against both learners and teachers in many schools is on record. With the upsurge of these acts, the demand for crisis intervention services in schools has increased significantly. Such systematic pressures need to be matched by enhanced support mechanisms in the form of in-service education and training (INSET) programmes for rural teachers.

Teachers show empathy, warmth and sincerity to learners in crisis. It seems that most teachers (86\%) in this survey were congruent that teachers show empathy, warmth and sincerity to learners in crisis. Showing empathy, warmth and sincerity to learners in crisis does not translate into crisis intervention action plans, training rural teachers in crisis intervention will equip them with the tools they require for effective crisis intervention obligations,

Teachers assess crisis situations and the learners in crises. Table 2 further on revealed that a high proportion of the respondents (82\%) indicated that teachers do not assess crisis situations and the learners in crises. Assessing the crisis situations is a crisis intervention skill which crisis interveners have to acquire and possess. This is confirmed by Hendricks and McKean (1995) who astutely point out that teachers as crisis interveners need to have good communication skills, conflict management skills and confrontation management skills so as to effectively assess crisis situations and the learners in crises.

Teachers ensure the safety of the victim learner by minimising the physical and psychological dangers that may affect him. Once again, Table 2 revealed that a majority of the respondents (70\%) indicated that teachers do not ensure the safety of the victim learner by minimising the physical and psychological dangers that may affect him. Ensuring the safety of the victim learner by minimising the physical and psychological dangers that may affect him is a basic crisis intervention skill required of crisis interveners, which most teachers do not have. James and Gilliland (2003) pinpoint six steps in basic crisis intervention skills. These steps are designed to operate as an integrated problem solving process.

$>$ Step 1 = Defining the problem: defining and understanding the problem from the client's viewpoint.

$>$ Step 2 = Ensuring the safety of the client: the intervener has to keep the client safe and try to minimize the physical and psychological dangers that may affect the client. 
$>$ Step 3 = Support Provision: the client must be informed that the intervener is there to support him and cares a lot about him.

$>$ Step 4= Exploring alternatives: the intervener assists the client to acknowledge that many alternatives exist and that some are better than others.

$>$ Step 5 = Execution of plans: this step involves designing action plans that will provide the client with an opportunity to restore his emotional equilibrium.

$>$ Step 6= Getting appropriate commitment: this step involves the intervener obtaining the commitment from the client before terminating the crisis intervention session.

Teachers begin with interviewing the victim learner to counseling him. Table 2 further on revealed that more than half of the respondents $(60 \%)$ indicated that teachers do not begin with interviewing the victim learner to counseling him. This aspect is very important in the crisis intervention process. It is part of the good communication skills which must be possessed by crisis interveners. Crow (1977) in Hendricks and McKean (1995,) pointed out that crisis intervention requires a special kind of communication. Proficiency in communication skills is indispensable in crisis intervention, beginning with interviewing the victim to counseling him. For this reason, the crisis intervener needs to integrate effective communication skills with relevant intervention techniques. Poor communication between the intervener and the client can hinder the process of crisis intervention. Communication involves not only speaking, but also good listening. The communication skills of the intervener should reach the level of excellence, as he needs to understand clients' messages and must possess skills and abilities which, inter alia, include identifying and understanding the levels of listening, identifying barriers to listening, promoting communication and providing feedback.

Teachers have approaches that schools have can employ to discourage and counteract acts of school violence. In conclusion, Table 2 revealed that a high proportion of the respondents (90\%) indicated that teachers do not have approaches that schools can employ to discourage and counteract acts of school violence. Although it is not always possible to prevent some acts of violence, it is nevertheless important for schools to explore and address school violence. These days acts of school violence are increasing at an alarming rate. While the rise in school violence can be attributed to violent learners, there are also instances where individuals who are not part of the school community commit acts of violence on school premises. In instances where learners themselves are involved, the element of bullying is prevalent. Although no known intervention plan can guarantee a prevention of such tragedies, nevertheless the school should have approaches that the teachers can employ to discourage and counteract acts of school violence. There are strategies that schools can use to prevent various forms of crises from occurring. Sandoval (2002) outlines these strategies as:

$>$ Educational workshops which consist of intensive training on topics that generate feelings and emotions. They are aimed at preventing and stopping mental problems that can occur in future. The content of these programs assists the children to reveal their feelings about what is happening in the social environment of the classroom and tries to liberate them from anxiety that may develop from crises that may emanate in the classroom.

$>$ Anticipatory guidance which involves introducing a learner intellectually to events that might happen in future and assist him to prepare realisable coping strategies. This type of guidance assists learners to adjust to novel settings and informs them on what can be anticipated, both emotionally and mentally.

$>$ Screening programmes which involve establishing procedures to recognise learners that are vulnerable to dangerous situations and to give them specially needed help at the right moment. Screening programmes involve issuing questionnaires to learners to establish precisely who is at high risk of not coping.

$>$ Consultation: In this instance, services of expert psychologists are enlisted to interact with teachers to assist them in dealing more effectively with the learners in crisis. These experts provide the teachers with best crisis intervention strategies that they can employ when dealing with learners in crisis.

$>$ Research: Sandoval (2002) submits that doing research is not often considered as a preventive activity, but if the crisis interveners gain more knowledge about the phenomenon through research, they will be in a better position to predict and control that phenomenon.

\subsection{Problems encountered by rural teachers when attempting to effect crisis intervention in their schools}

This section was an open-ended question, where teachers were required to mention the problems they encounter when trying to effect crisis intervention in their schools. In analysing the responses, the problems were ranked in the order of frequency as follows:

- The teachers do not have techniques, strategies, and skills needed to help the learners in crisis (95\%).

- Schools are increasingly becoming places where traumatic events occur and the problem of crisis intervention in schools does not avail itself to simple solutions (86\%). 
- Crisis is omnipresent in communities riddled with crime, violence, the HIVIAIDS pandemic, rape and sexual assault, death and illness, substance abuse and so forth. Consequently, stress experienced by learners from these communities increases, thus leading the learners to increased emotional distress (75\%).

- The communities expect the provision of crisis intervention services in schools (58\%).

\subsection{Teachers' suggestions on improving crisis intervention in their schools}

In another open-ended question, teachers were required to make suggestions on what can be done to improve crisis intervention in their schools. In analysing the responses, the suggestions were ranked in the order of frequency as follows:

- Teachers involved in crisis intervention need special training. They cannot rely only on common sense and instinct (96\%).

- Teachers trained in crisis intervention can do much to reduce learners' stress and to facilitate coping efforts (82\%).

- Crisis intervention is one issue that requires the sustained involvement and commitment of all social structures with an interest in education, such as the churches, law-enforcement agencies, parents, the private sector and learners themselves (70\%).

- Rationalise the crisis intervention functions (56\%).

- Understand the legal implications of crisis intervention (52\%).

\section{Concluding Remarks}

This study explored the experiences of rural teachers in crisis intervention in schools. Although all the participants were supportive of crisis intervention in schools, their experiences also illuminate challenges associated with crisis intervention. One of the great challenges is lack of training of teachers in crisis intervention skills and strategies as they are expected to be crisis interveners at all costs. In conclusion, it needs to be mentioned that the victims of crises face serious problems. Effective crisis intervention education is an important component in addressing these problems. If crisis intervention were incorporated into the teacher-education curriculum, teachers would be better prepared to assume their roles as crisis interveners in schools.

On the strength of the above-mentioned conclusion, the following is recommended:

- The Creation of Safer Schools: The crisis of violence and death in schools calls for the creation of safer schools. According to Goldstein and Kodluboy (1998) in James and Gilliland (2003), school safety is not only a matter of physical well being, but also a case of psychological well being. It should be noted that violence in schools comes from various angles such as bullying, gangs and violent learners. School safety must therefore be approached from both immediate and long-term perspectives and must always incorporate intervention strategies. All social structures with an interest in schools must make the prevention of school violence a priority. It is therefore recommended that experts in other areas such as social welfare, law enforcement, mental health services and psychologists must assist the schools in developing a comprehensive guide to school safety. Such a guide should recommend appropriate intervention strategies for all learners, including learners that are considered to be at risk.

- Controlling school access to outsiders: It is important that all schools be fenced and have monitored gates. The services of security guards or school cops should be enlisted to check on all people entering the school. In some instances, metal detectors can be used to screen for weapons.

- Establishing training programmes for teachers to function as school - based crisis interveners: Schools should establish training programmes for teachers involved in crisis intervention. These programmes will provide a means of ensuring that teachers receive extensive training in all aspects of emotional first aid and crisis intervention. The trained teachers will need to adequately demonstrate their knowledge and ability in crisis intervention. Trained teachers, at least in basic crisis intervention skills, will be in a position to explore the feelings and emotions of the affected learners. 


\section{References}

France K (1990). Crisis Intervention: A Handbook of Immediate Person-to-Person Help. Second Edition. Springfield: Charles C Thomas Publishers.

Greenstone J \& Leviton C (2002). Elements of Crisis Intervention: Crises and How to Respond to Them. Second Edition. Pacific Grove: Brooks / Cole.

Hendricks J \& McKean J (1995). Crisis Intervention. Springfield: Charles C. Thomas Publishers.

James R \& Gilliland B (2003). Crisis Intervention Strategies. Belmont: Wadsworth Publishing Company.

Kanel K (2003). A Guide to Crisis Intervention. Pacific Groove: Wadsworth Publishing Company.

Kumar R (20140. Research Methodology: As Step-by-Step Guide for Beginners. New Delhi: SAGE Publications.

McMillan J \& Schumacher S (2006). Research in Education: Evidence-Based Inquiry. Boston: Allyn \& Bacon.

Myer R (2001). Assessment for Crisis Intervention: A Triage Assessment Model. Belmont: Wadsworth /Thomson Learning.

Roberts A (19900. Crisis Intervention Handbook. Assessment, Treatment, and Research. Belmont: Wadsworth Publishing Company.

Sandoval J (2002). Handbook of Crisis Counseling, Intervention and Prevention in the Schools. Second Edition. London: Lawrence Erlbaum Associates Publishers. 